The average number of men under restraint was two; of women, fonr. The average number of men in socinsion was five; of women, eight.

The foregoing are the principal pointe of interest refarred to in the Report.

There are probably como of our resder who are wont to regard the Dutch as a people

"The always ply the pamp, and neree think

They can be safe, bat at the rato they alnk,

That bed like cannibels on other stret,

And serve thetr cousin-germans up in dislies ["-Budibras

This, however, is but a travesty; and that the Datch are capable of high emotions and benevolent designs they have proved, by the means they have taken to provide for the caro and the cure of their insane population.

\section{H. TUKE.}

Sulphwric Acid, r. Orine.

My dear Sir,-If you think that the use of sulphuric acid diluted with water, as a chemical agent for disimpregnating floor, or other boards saturated with urine, is not as well known to the superintendents of aylums generally as to myself, may I ask you to gire a place to this letter in the next number of our Journal.

It is of conrse very desirable to have wooden in preference to othor floors; but often in wet and dirty, and occnsionally also in other wards, these become in the course of tine partially saturated with arine, much discolored, and very offensive. No scrubbing or scalding will effect more than a temporary improvement in such floors, for the rood has absorbed and holds mach, becoming a reservoir for the perpetual exhalation of the volatile ammonia

Let such a stained floor have poured over it a mixture of one fluid ounce of sulphuric acid with twenty or twenty-four ounces of water; let the liquor be diffused in an even stratum, and lie for twentyfour hours.

The first effect of the application will be effervescence, then the evolntion of a strong urinous odour (soon disappearing), and lastly, in the course of the drying up, the deposition of a white film (sulphate of ammonia) all over the area treated, varying in ambunt in different parts, according to the dopth of stain.

Lastly, let the salt be washed off, aud if the boards bo not restored to something like the color of clean deal, this may be obtaincd by a second or third repetition of the process. All odour of urine will be gone and the room rendered sweet.

I do not find the use of the acid on similarly stained floor-stones so successful. The action is unequal; some parts resisting it, as if protected by something greasy. A further trial, howerer, on stone, will be worth making, aner well cleansing the surface with a strong solution of washing-soda. The acid may bo applied to urine-stained crib-bedsteads, or in any situation to wood.

The principle, that of converting a volatile into a fixed salt, which may be removed, appears suffeiently good, and I beg to assure you that the effect is very gratifying in practice.

There is nothing novel in the idea, which, es far as I know, and as regards this sort of application of it, is due to my friend and teacher, Dr. Hitch. It can be considered as no more than an extension of its ase in pillows containing bran, to catch the urine from persons confined to bed with sores, which he communicated to the lancet, I believe, some years since.

I remain, your obedient servant,

JAMIES E. HUXIEY.

Doonty Lunutle Asylum, Maldetose, October 10, 1854.

Treatment of Cholera.

Essex Lanattc Asylum, Nor. 6th, 1884.

My dear Sir,-In compliance with your request, I send you a short statement regarding the cholcra cases which have taken place in this asylum.

The disease first appeared on the 8th day of September last, and has cansed considerable mortality among the unfortunate lunatics.

Two wards, one on the male, and another on the female side of the house, were immediately set apart for those attacked, and attendants were appointed, whose duty it was to attend entirely upon the cholera cases.

The epidemic, however, spread, and from the day of its first appearance up to the 15 th October, nineteen cases of Asiatic cholera and ten cases of choleraic diarrhear took place; of these, twelve recovered and serenteen died. During the same period, about seventy cases of diarrhas without collapso were ander treatment.

My treatment of cholera was to give two grains of calomel every fifteen minntes for the first five hours, then two grains every half hour for three hours, and afterwards two grains every hour for from twelve to fifteen hours, with cold spring water to drink. Mnstard sinapisms were applied to the extremities and abdomen, and friction was also nsed. In four of the cases stimulants were administered, which seemed to aggrarate the symptoms.

Having had considerable experience when in India in treating the disease, the mode which I then considered and found most successful was calomel in small doses frequently repeated, and although the deaths have been large here in proportion to the number attacked, this circumstance arises in a great measure from the weak state of many of the patients previous to the attack.

I have no hesitation in saying, that I would again adopt the same mode of treating the disease, should this institution be again unfortunntely visited by cholera.

$$
\text { Yours faithfally, }
$$

\section{C. CAMPBELI.}

WWo are informed that there has been a severe outbreak of cholers in the Hoxton Asylum. All the cases, with one exception, happenod during the flrot week in October. Nineteen male and seven female patients died. We do not know that the pestllenco hes bitherto inraded any other asylum.-2D.]

\section{Inquest at the Norfolk County Asylum.}

On the 28rd ult. an inquest was held at Thorpe, before Mr. Pilgrim, one of the county coroners, on the body of William Sixer, a man aged 36, who died suddenly that morning, in the County Iunatic Asylam. Evidence was adduced to the effect that the deceased was admitted on the 15th of July last; that 